\title{
Manufacturing methods for medical artificial prostheses- a review
}

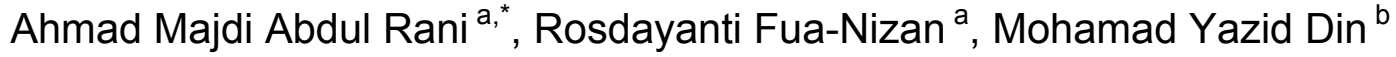 \\ a Mechanical Engineering Department Universiti Teknologi PETRONAS, Bandar Seri Iskandar, 32610 Perak, Malaysia \\ ${ }^{b}$ Orthopaedic Department, Hospital Tuanku Fauziah, Jalan Tun Abdul Razak, Pusat Bandar Kangar, 01000 Kangar, Perlis, Malaysia \\ * Corresponding author: majdi@utp.edu.my
}

\section{Article history}

Received 3 October 2017

Accepted 10 December 2017

\begin{abstract}
The main objective of this paper is to review the manufacturing methods that can be used for fabricating medical prostheses. The medical prostheses have different functions and applications. Selection of manufacturing method is made based on the material, design, and mechanical properties of the prostheses. The conventional manufacturing methods that had been applied for manufacturing prostheses are machining, incremental sheet forming and investment casting. The combination of computer numerical control and additive manufacturing has been able to improve the process efficiency of these methods. However, direct fabrication by additive manufacturing has been able to replace the conventional method with better process efficiency and product accuracy.
\end{abstract}

Keywords: Prostheses, biomedical, manufacturing, machining, additive manufacturing

\section{INTRODUCTION}

Prosthetics is one of many division in medicine that focuses on surgical procedures for replacing the body parts that have been removed due to illness or accidents with artificial components. Biomedical and bioengineering are the fields that are responsible for providing the engineering and scientific solutions to medical and biological problems respectively. For prosthetics, the issue is to design and fabricate artificial components as replacement of the resected parts. The objectives of these artificial components does not only to replace the human part but also to restore its normal function. These technologies should be able to facilitate recovery and the improvement of human biological functions continuously. There are two types of biomechanical prostheses, ready-made prostheses and custom-made prostheses. Ready-made prostheses are designed and manufactured in standard sizes. Unlike ready-made prostheses, custom-made prostheses are made to fit the patient and are designed via reversed engineering method.

This type of prostheses are usually designed based from the medical image of the patients' anatomy through reversed engineering and are made upon demand. These prostheses can be fabricated by using biomaterials. These biomaterials are engineered based on specific application and must not cause harm to human body environment. Some examples of prostheses are artificial cochlear for neural engineering, artificial skin tissue for tissue engineering, artificial heart valve for cardiovascular engineering, artificial joints such as knee and hip implants, and dental implants. The selection of suitable manufacturing method is also made based on these standard criteria which are material, application, and design. This paper will review the manufacturing methods that can be apply for fabricating medical prostheses for various applications using different types of materials.

\section{MANUFACTURING METHOD}

\section{Conventional Manufacturing Methods}

One of conventional manufacturing method that can be used to manufacturing prostheses is machining. It is a method that involves material removal process from a block of raw material that is conducted with a cutting tool (Fig. 1).

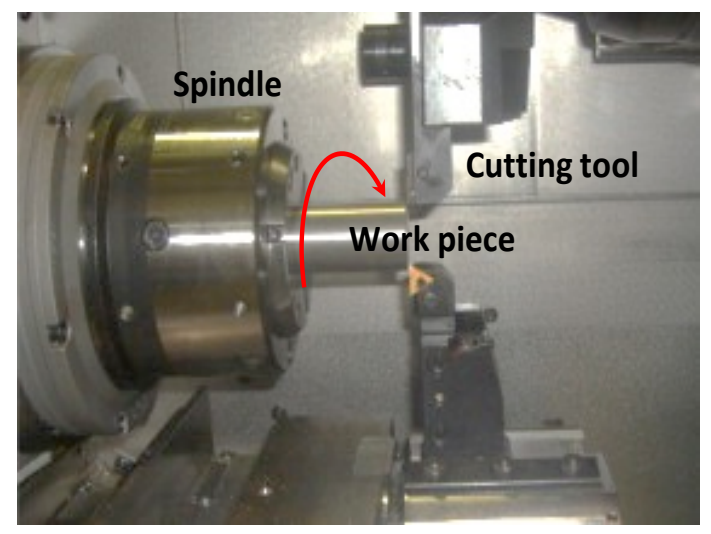

Fig. 1 Turning operation (Budak \& Ozturk, 2011)

Machining used to be one of the main manufacturing methods for fabricating orthopaedic implants. Compared with advanced manufacturing technologies, machining is considered to be fairly cost effective and user-friendly. This method can also be used to improve the surface finish of the finished product. However, this method used to be limited to simple and straightforward design because the conventional machining equipment generally was available in three working axes. Hence, it was highly recommended for manufacturing implant components with simple designs such as pins. The 
combination of machining parameters such as the speed can actually determine the quality of the finished products (Ahilan, Kumanan, Sivakumaran, \& Edwin Raja Dhas, 2013). However, optimum working parameters need to be determined according to the working material in order to achieve good surface finish and this stage can increase the fabrication process.

With the development of advanced manufacturing technologies, conventional machining system was replaced by computer numerical control $(\mathrm{CNC})$ machining and the available 5 axes $\mathrm{CNC}$ machine has provide better flexibility for machining to sculpture freeform surfaces The aid of $\mathrm{CNC}$ has also managed to reduce the process duration, making it more user-friendly with minimum requirement of human input. This is because the user only need to input their desired design in computer-aided design (CAD) format and the computer will automatically generate the tool path into G-code. G-code is generic control language specifically used for $\mathrm{CNC}$ machines. This set of code contains the coordinate and position of cutting tool and the computer will automatically calculate the route of the cutting tool on the work piece. Another advancement in machining is the development of micromachining. This method utilizes laser aided technology (Wall, 2012) and have the ability to modify the surface structure of polymer components with micro-scale surface texture. It can also be applied for manufacturing tiny implant components as well. However, the limitation of machining is that the nature of the processing where deposition of raw material create waste that could increase the cost (Cronskär, Bäckström, \& Rännar, 2013a).

Incremental sheet forming (ISF) on the other hand is a forming process of sheet metal through continuous forming. This method uses a rotating tool through progressive increase in pressure. A sheet metal is fixed on a clamp and a rotating forming tool will gradually apply pressure on the sheet metal (Fig. 2). This method is considered to be user friendly because it is adaptable to $\mathrm{CNC}$ milling equipment.

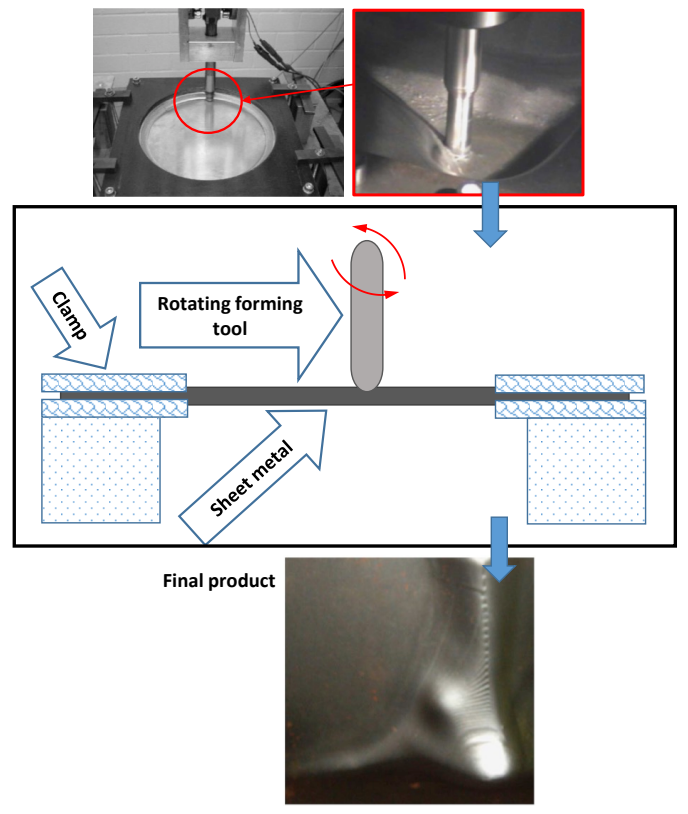

Fig. 2 SPIF schematic diagram (Ambrogio, De Napoli, Filice, Gagliardi, \& Muzzupappa, 2005)

There are a two basic techniques of ISF which are single-point (SPIF), and two-point (TPIF). SPIF is a method that uses a single point contact while TPIF utilizes two points contact on the sheet metal. This method can produce asymmetrical product via spinning, flow forming, and shear forming across the blank (Gatea, Ou, \& McCartney, 2016; Jeswiet et al., 2005). ISF is a die-less manufacturing method that is process more cost effective and less raw material waste compared to machining. However, ISF processing time is directly dependent on the sheet thickness, material and part geometry. Fabricating a complex design could be lengthy. Furthermore, determining the process parameters can be a challenge especially with a new materials. Unsuitable working parameter could lead to sheet material failure during the fabrication process. Therefore, this method is more suitable for straightforward geometry and smallbatch manufacturing such as a customized cranial implant for cranial plate reconstruction (Lu, Ou, Shi, Long, \& Chen, 2016). Some studies was conducted in order to improve ISF. Conventional ISF was able to enhanced with the application of laser as forming tool (Hino, Kawabata, \& Yoshida, 2014). This technology had able to improve the accuracy of the process, the formability of the sheet material and at the same time reduce the residual stress on the finished product. Besides, preliminary analysis of the material's mechanical properties could also improve the fabrication duration especially for new materials.

Unlike ISF, investment casting on the other hand is a manufacturing method that uses patterned moulds for casting (Pattnaik, Karunakar, \& Jha, 2012). Molten metal is poured into the mould and left to cool to form solid metal. The mould then is removed from the solid. Investment casting used to be an alternative method for manufacturing metal medical implants. However, the conventional method for fabricating mould was expensive and time consuming. To overcome this limitation, additive manufacturing was introduced for fabricating the mould. Additive manufacturing technology had able to fabricate mould from variety of material such as wax and silicone. Furthermore, the product of the investment casting has with better quality and high accuracy (R. Singh, Singh, \& Kapoor, 2014). This combination has managed to reduce the lead time and has made investment casting economically more effective as well. Compared with wax, silicone made mould are much more easily to remove from the solid product as well.

Investment casting is well known for manufacturing of prosthodontics that focuses on designing and fabricating artificial implants for mouth parts including teeth. However, the quality of implant fabricated is depending on the quality of the mould. High quality was pattern will produce high accuracy implant. Furthermore, implant with excellent fit will have better reliability and the quality of the mould is depending on the condition of the wax and the processing parameters as well. In order to overcome this limitation, studies had been conducted and had able to achieve the optimum working parameters for different types of wax, while at the same time improve the quality of the product as well (Kumar, Ahuja, \& Singh, 2016; J. Singh, Singh, \& Singh, 2017).

\section{Additive Manufacturing Methods}

Additive manufacturing (AM) is a manufacturing method by material deposition in layers that builds a part based on standard tessellation language (STL) formatted file from computer-aided design (CAD) software. The product of AM can either be designed by the digital scan of the part and from the conceptual part design. It is a direct and straightforward method that is more feasible and relevant for manufacturing medical implants. The general processing flow of $\mathrm{AM}$ is illustrated in Fig. 3.

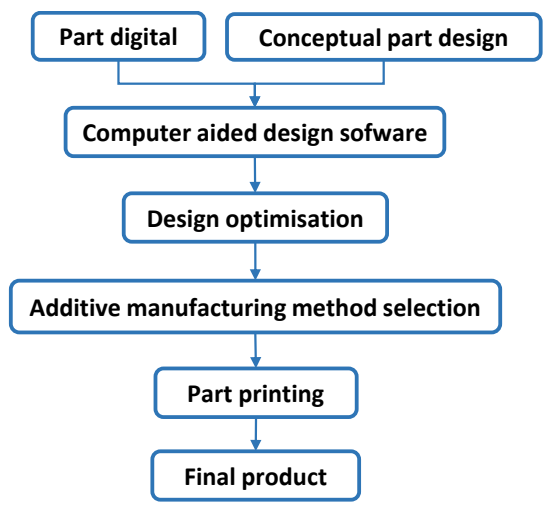

Fig. 3 Additive manufacturing general process flow

AM has the flexibility of using variety of available materials with desired customizations such as porosity and surface roughness as well. AM can classified into three working materials which are solid based, 
liquid based and powder based AM (Ventola, 2014). Fused deposition manufacturing (FDM) is one application of solid based AM. This method eject thin filament of polymer through an extrusion nozzle on a moving platform as illustrated in Fig. 4.

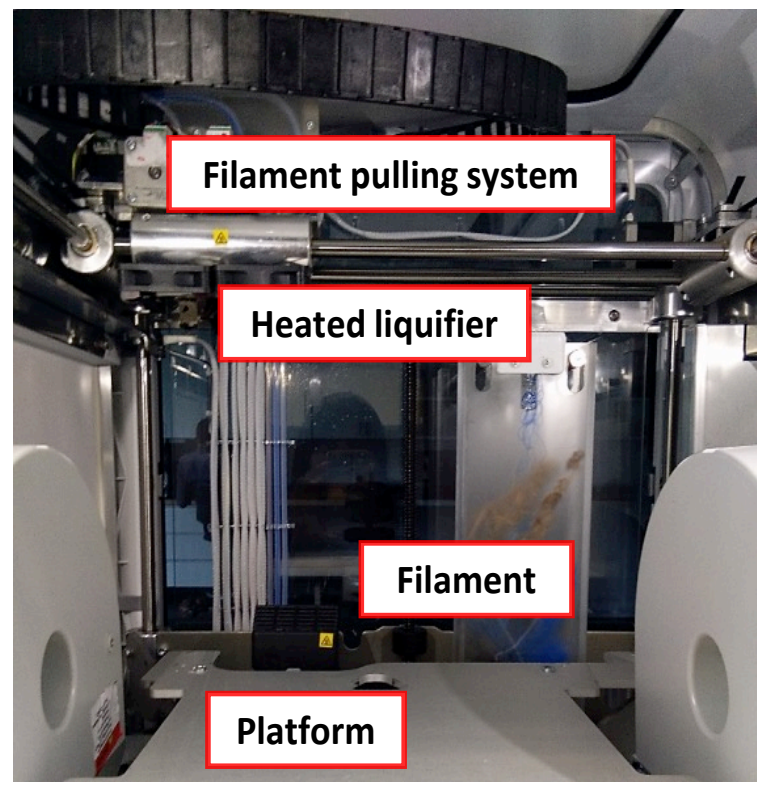

Fig. 4 FDM equipment

As this method is conducted in a closed working space, the material will become solid as it comes into contact with the previous layer. FDM is the most appropriate manufacturing method polymer based implant because it provides full control on the working parameters where the users will be able to customized the mechanical properties of the product (Carneiro, Silva, \& Gomes, 2015). Furthermore, the final product will possess enough strength and require minimum post-processing stages. FDM is known to be cost effective and user friendly as well. However due to the limited material available, FDM application for prostheses is limited as compared to metal based AM. One example of biocompatible polymer for medical application that is available for FDM is polypropylene. This material possess excellent strength and is common in suture for surgical procedures (Carneiro et al., 2015; "Polypropylene Suture," n.d.). Due to this limitation, FDM is currently being used for fabricating medical models that are used for pre-surgery planning and educational purposes (El-Katatny, Masood, \& Morsi, 2010). Another medical application of FDM is for fabricating orthoses which are limb brace devices that are used for supporting limbs during recovery such as wrist splint (Fig. 5).

Liquid based AM on the other hand perform solidification process of liquid material via curing. Unlike solid material, liquid material require curing for solidification and to improve the mechanical properties of the solid. Some examples of liquid based $\mathrm{AM}$ are stereolithography (SLA), and continuous liquid interface production (CLIP). SLA's building process is known as photopolymerization. It is a process of polymer solidification by the application of ultraviolet (UV) rays that act as catalyst for the liquid resin reaction (Melchels, Feijen, \& Grijpma, 2010) (Fig. 6). It is a continuous process of making the part layer by layer until a solid product is constructed.

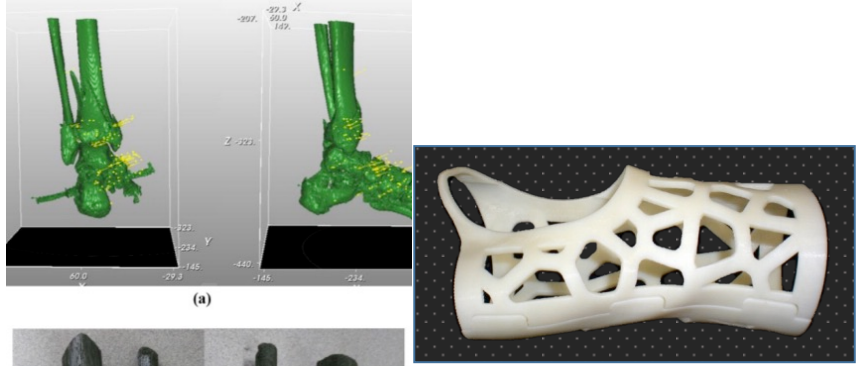

Fig. 5 Tibial model (Yap et al., 2017) and wrist split fabricated by FDM (Paterson, Bibb, Campbell, \& Bingham, 2015)

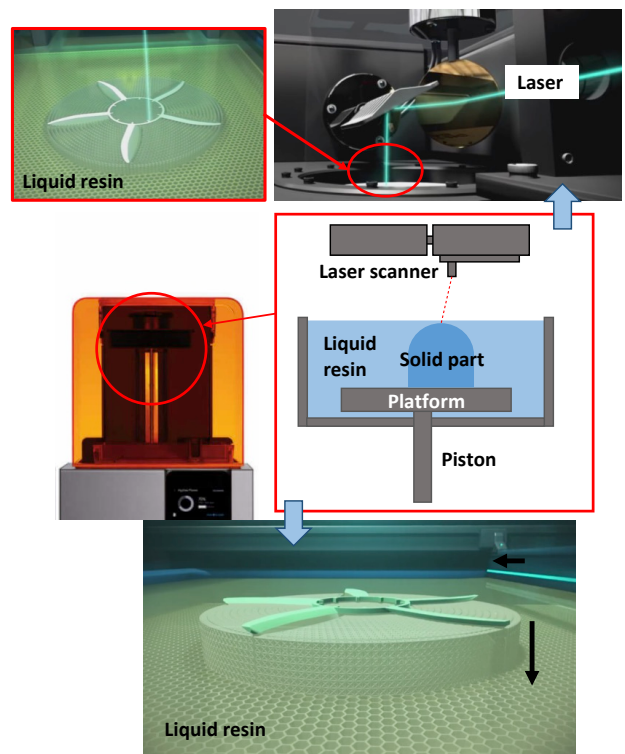

Fig. 6 SLA schematic diagram ("Stereolithography," n.d., "The Best SLA 3D Printers," n.d.)

SLA is known to have excellent dimensional accuracy and surface finish for polymer based products (Zhou, Ye, \& Zhang, 2015). Some applications of SLA are including wax ear (Coward, Trevor J.; Watson, Roger M.; Wilkinson, 1999), temporal bone prototype (Suzuki et al., 2004), and mould for cranial implant (Wurm, Tomancok, Holl, \& Trenkler, 2004). Due to this advantage, nano-SLA technology was developed for the purpose of manufacturing micro devices with complex geometry (Ha \& Yang, 2014) as well. Furthermore, micro-SLA (MSLA) was also developed with the ability to produce fine resolution scaffold with excellent mechanical properties that is similar to bone. This technology is also showing great potential in the fabrication of customized tissue scaffold for cell regeneration. Another development of the conventional SLA is the multi-material SLA that have a rotation resin tank. This technology has the ability to build parts by using different material at the same time (Choi, Kim, \& Wicker, 2011; Wong \& Hernandez, 2012). However, support structure is needed for building parts with complex design because the liquid resin only function for aiding the solidification process and not for supporting the material.

Staircase effect (Fig. 7) is the surface degradation (Arni \& Gupta, 2001; Janusziewicz, Tumbleston, Quintanilla, Mecham, \& DeSimone, 2016) by SLA due to the layer-by-layer fabricating nature. Additional post processing stages are required in order to improve the surface roughness, however will lengthen the manufacturing time and increase the cost as well. Due to this limitation, continuous liquid interface production (CLIP) was developed. 


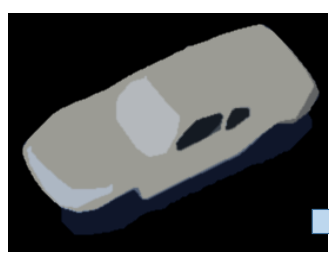

CAD model

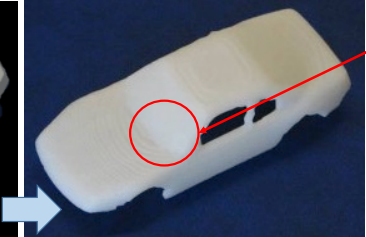

Solid product

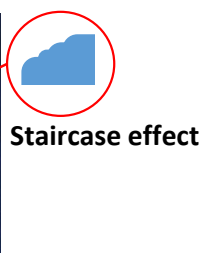

Fig. 7 Staircase effect on finished product fabricated by SLA (Arni \& Gupta, 2001; Galantucci, Percoco, \& Dal Maso, 2008)

CLIP is another modified version of the conventional SLA that was developed to improve this limitation (Janusziewicz, Tumbleston, Quintanilla, Mecham, \& DeSimone, 2016). CLIP deposits continuous liquid compound (Yang, Zeng, Vieira, \& Olsson, 2016) that manipulates oxygen-comprised area, known as the 'dead zone' (Fig. 8 ). It is a small gap in between the oxygen absorbent window and curing resin. Besides from producing better product with excellent surface finish, CLIP promotes faster building process as well.

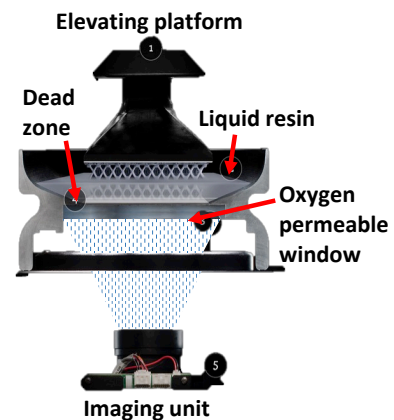

Fig. 8 CLIP equipment (“CLIP Process," n.d.)

Although this technology is relatively new, it was mentioned as one of alternative polymer based manufacturing method for dental implants (Stansbury \& Idacavage, 2016). Furthermore, this method has the ability to process biological and elastic materials (J. R. Tumbleston et al., 2015) that is suitable for artificial tissue and cartilage. These advantages will definitely open up more possibilities of applying this method in manufacturing of medical implants.

Powder-based AM is when the working materials comes in the form of powder. There is another liquid based AM which is Polyjet. Although this method has the ability to fabricate parts with high accuracy (Salmi, Paloheimo, Tuomi, Wolff, \& Mäkitie, 2013) in multiple colours, this method is known to fabricate medical models only. This is because there are very limited biomaterial that is available for Polyjet. Compared with the solid and liquid based AM, powder based AM have wider range of available materials such as polymer, metal and ceramic. Unlike the previous two AM types, most of powder based AM equipment are used in manufacturing metal based medical implant. The AM equipment that are working by using powder material are laser sintering, selective laser melting (SLM), electron beam melting (EBM), and laser engineered net shaping (LENS). Selective laser sintering (SLS) is a manufacturing technique that solidify powder material through sintering. Sintering is a solidification process that uses thermal energy to fuse the powder particles together at temperature in between the melting temperature and half of the melting temperature (Kruth et al., 2005). As the thin layer of powder is laid upon the platform, the laser will start to sinter the powder and the platform will move for another layer of powder. SLS have the ability to provide control over the geometry and porosity of the final product, which is excellent for the fabrication tissue scaffold (Mazzoli, Ferretti, Gigante, Salvolini, \& MattioliBelmonte, 2015). Conventional SLS equipment has wide variety of process materials such as polymer, and metal-ceramics mixture (Tiwari \& Pande, 2014). Direct Metal Laser Sintering (DMLS) was developed specifically for metals and metal alloys. Unlike SLA, sintering building process does not require support structure because the excess powder in the powder bed could provide surrounding support for the solid product (Fig. 9).

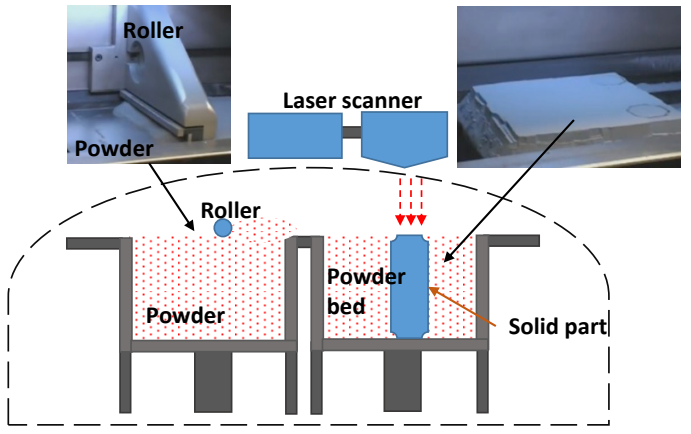

Fig. 9 General schematic diagram of DMLS ("3D Metal Printed Parts," n.d.; Frazier, n.d.)

SLM has similar working principle to DMLS. . The difference is that SLM employs laser beam with higher power range that heats the material up to the melting temperature. This full melting mechanism was originally developed for the purpose of minimizing post processing stage (Kruth et al., 2005). This melting mechanism is highly recommended for metals and as well as ceramics. This method is highly recommended for metals and as well as ceramics because it produce lightweight but strong and robust products. The pore structure of the part can also be customized. Moreover, the customization of the working parameter could also improve the density and strength of the final product (Read, Wang, Essa, \& Attallah, 2015; Yadroitsev, Krakhmalev, \& Yadroitsava, 2014). However, the working parameters need to be customized for different materials, making this method more difficult to control (Pacurar \& Pacurar, 2016). Another method that utilizes metal powder is EBM. This technology is known to produce high accuracy parts by utilizing electron beam to melt the powdered material (Fig. 10).

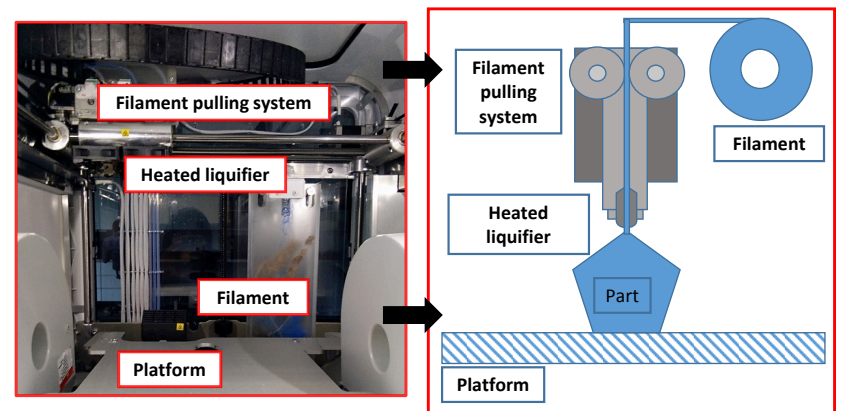

Fig. 10 EBM equipment and schematic diagram (“EBM Hardware," n.d.)

EBM is more time efficient and user friendly compared to laser UV based AM such as SLA (Harryson \& Cormier, 2003). This is because electron beam energy possesses higher density that able to increase the building process (Parthasarathy, Starly, Raman, \& Christensen, 2010). This method also has the ability to improve the material's mechanical properties and strength (Edwards, O'Conner, \& Ramulu, 2013; Murr, 2015). Furthermore, EBM could produce product with excellent accuracy which is important for customized implant such as knee and hip implants (Cronskär, Bäckström, \& Rännar, 2013b; Harryson \& Cormier, 2003). Titanium alloy is a common material for knee and hip implant and the studies conducted on EBM by using titanium alloy shows that the solid titanium possess excellent strength and hardness (Edwards, O'Conner, \& Ramulu, 2013; Tan et al., 2015). Continuous study has been conducted as well and EBM was seen to have potential in manufacturing metal implant as well.

Laser engineered net shaping method (LENS) is another type of AM that utilized powder material for building solid parts. Unlike other method, LENS solidifies melted powder metal in a melted substrate (Cong \& Ning, 2017). The process of melting the substrate 
and the powder metal is conducted by laser radiation as shown in Fig. 11

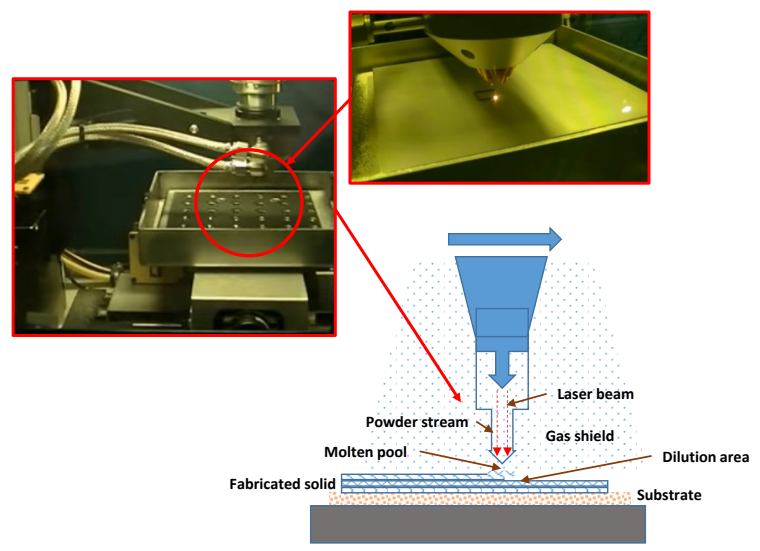

Fig. 11 LENS schematic diagram (Cong \& Ning, 2017; "LENS 450 System," n.d.)

LENS has the flexibility of processing most type of powdered metal alloy and ceramic with high complexity and customized porosity (Mallik, Rao, \& Kesava Rao, 2014; Niu et al., 2016). However, the final product is prone to surface deformation due to high solidification rate (Gu, Meiners, Wissenbach, \& Poprawe, 2012). Due to this limitation, a study on heat treatment was conducted in order to enhance the hardness of the product (Cong \& Ning, 2017). For polymer on the other hand, ultrasonic vibration method was developed and has able to improve the quality of polymer parts fabricated by LENS (Cong \& Ning, 2017).

\section{CONCLUSION}

Although conventional manufacturing technology had been enhanced with the aid of computer-aided software, advanced manufacturing technology has seemed to catch up in manufacturing medical implants. Material removing methods have become less preferable due to the material wastage and longer operation time. These limitations in conventional manufacturing had encouraged the development of advanced manufacturing technology through reversed engineering approach. Reversed engineered implants mainly focus on the geometrical accuracy and functionality. These customized implants are designed from the medical images of human part based on specific anatomy. Integrated approach that was developed has able to increase the processing duration and reduce material waste as well. Another advantage of $\mathrm{AM}$ in comparison with conventional manufacturing methods is the ability to customize the micro structure of the product according to the application. The micro structure of the implant is very important especially for bone because upon healing, the bone need to grow into the implant. The porosity and strength of the implant could also be further enhanced with application of postprocessing methods. However, despite these advantages there are some limitations of advanced manufacturing method. This method has managed to reduce the material waste but the overall operation and equipment is still considered to be costly. This aspect is mainly subjective because it is closely related to the material selection and production volume (Campbell, Bourell, \& Gibson, 2012). Besides, obvious trend has been observed that shows the decrement in the equipment price over the past decades (Emelogu, Marufuzzaman, Thompson, Shamsaei, \& Bian, 2016). This has proven that the advanced technology will be more affordable in the future. Another weakness of additive manufacturing is that it is dependent on other technologies for support (Gibson, 2005). Medical prostheses fabricated by additive manufacturing are required to undergo finishing stage. In this stage, the product must be polished, coated and sterilized to suit the human body environment. These processes increase the manufacturing duration for the implant. Despite of all these limitations, advanced manufacturing is still gaining popularity and more recognition. The public has become more aware of this technology and it has manage to attract many research and studies dedicated for this technology. The equipment has become portable and more user friendly as well. Soon, the medical officers and surgeons should be able to operate the equipment with minimum supervision from technical experts. Available in-house equipment in the hospital could also reduce the gap in between implant designing and fabrication.

\section{ACKNOWLEDGEMENT}

This paper publication was supported by the Universiti Teknologi Petronas.

\section{REFERENCES}

3D Metal Printed Parts. (n.d.). Retrieved from http://www.prweb.com/releases/cadcamconnect/gpiprototype dmls/prweb9950081.htm

Ahilan, C., Kumanan, S., Sivakumaran, N., Edwin Raja Dhas, J. (2013). Modeling and prediction of machining quality in CNC turning process using intelligent hybrid decision making tools. Applied Soft Computing Journal, 13(3), 1543-1551.

Ambrogio, G., De Napoli, L., Filice, L., Gagliardi, F., Muzzupappa, M. (2005). Application of incremental forming process for high customised medical product manufacturing. Journal of Materials Processing Technology, $162-163,156-162$.

Arni, R., Gupta, S. K. (2001). Manufacturability analysis of flatness tolerances in solid freeform fabrication. Journal of Mechanical Design, 123, 148156.

Budak, E., Ozturk, E. (2011). Manufacturing technology dynamics and stability of parallel turning operations. CRP Annals, 60, 383-386.

Campbell, I., Bourell, D., Gibson, I. (2012). Additive mnufacturing: Rapid prototyping comes of age. Rapid Prototyping Journal, 18(4), 255-258.

Carneiro, O. S., Silva, A. F., Gomes, R. (2015). Fused deposition modeling with polypropylene. Materials and Design, 83, 768-776.

Choi, J. W., Kim, H. C., Wicker, R. (2011). Multi-material stereolithography. Journal of Materials Processing Technology, 211(3), 318-328.

CLIP Process. (n.d.). Retrieved from http://www.carbon3d.com/clip-process

Cong, W., Ning, F. (2017). A fundamental investigation on ultrasonic vibration-assisted laser engineered net shaping of stainless steel. International Journal of Machine Tools and Manufacture, 121, 61-69.

Coward, T. J., Watson, R. M., Wilkinson, I. C. (1999). Fabrication of a wax ear by rapid-process modeling using stereolithography. International Journal of Prosthodontics , 12(1), 20-27.

Cronskär, M., Bäckström, M., Rännar, L.-E. (2013a). Production of customized hip stem prostheses - a comparison between conventional machining and electron beam melting (EBM). Rapid Prototyping Journal, 19(5), 365-372.

Cronskär, M., Bäckström, M., \& Rännar, L.-E. (2013b). Production of customized hip stem prostheses - a comparison between conventional machining and electron beam melting (EBM). Rapid Prototyping Journal, 19(5), 365-372.

Edwards, P., O'Conner, A., Ramulu, M. (2013). Electron beam additive manufacturing of titanium components: properties and performance. Journal of Manufacturing Science and Engineering, 135(6), 61016.

El-Katatny, I., Masood, S. H., Morsi, Y. S. (2010). Error analysis of FDM fabricated medical replicas. Rapid Prototyping Journal, 16(1), 36-43.

Emelogu, A., Marufuzzaman, M., Thompson, S. M., Shamsaei, N., Bian, L. (2016). Additive manufacturing of biomedical implants: A feasibility assessment via supply-chain cost analysis. Additive Manufacturing, 11, 97-113.

Frazier, W. E. Metal additive manufacturing: A review. Journal of Materials Engineering and Performance, 23(6), 1917-1928.

Galantucci, L. M., Percoco, G., Dal Maso, U. (2008). A volumetric approach for STL generation from 3D scanned products. Journal of Materials Processing Technology, 204(1-3), 403-411.

Gatea, S., Ou, H., McCartney, G. (2016). Review on the influence of process parameters in incremental sheet forming. The International Journal of Advanced Manufacturing Technology, 87(1-4), 479-499.

Gibson, I. (Ed.). (2005). Advanced Manufacturing Technology for Medical Applications: Reverse Engineering, Software Conversion and Rapid Prototyping. England: Wiley.

Gu, D. D., Meiners, W., Wissenbach, K., Poprawe, R. (2012). Laser additive manufacturing of metallic components: materials, processes and mechanisms. International Materials Reviews, 57(3), 133-164.

Ha, C. W., Yang, D. (2014). Fabrication of micro open structure using 3D Laser scanning method in nano- stereolithography. International 
Conference on Manipulation, Manufacturing and Measurement on the Nanoscale (3M-NANO), 27-31 October 2014. Taipei, Taiwan: IEEE, 2731.

Harryson, O. L. A., Cormier, D. (2003). Direct fabrication of metal orthopedic implants using electron beam melting technology. Solid Freeform Fabrication Symposium, 4-6 Aug, 13, Austin, Texas, 439-446.

Hino, R., Kawabata, K., Yoshida, F. (2014). Incremental forming with local heating by laser irradiation for magnesium alloy sheet. Procedia Engineering, 81, 2330-2335.

Janusziewicz, R., Tumbleston, J. R., Quintanilla, A. L., Mecham, S. J., DeSimone, J. M. (2016). Layerless fabrication with continuous liquid interface production. Proceedings of the National Academy of Sciences of the United States of America, 113(42), 201605271.

Jeswiet, J., Micari, F., Hirt, G., Bramley, A., Duflou, J., Allwood, J. (2005). Asymmetric single point incremental forming of sheet metal. CIRP Annals - Manufacturing Technology, 54(2), 88-114.

Kruth, J.-P., Mercelis, P., Van, J., Froyen, V. L., Rombouts, M., Vaerenbergh, J. Van, Froyen, L. (2005). Binding mechanisms in selective laser sintering and selective laser melting Binding mechanisms in selective laser sintering and selective laser melting. Rapid Prototyping Journal , 11(3), 26-36.

Kumar, P., Ahuja, I. S., Singh, R. (2016). Experimental investigations on hardness of the biomedical implants prepared by hybrid investment casting. Journal of Manufacturing Processes, 21, 160-171.

LENS 450 System. (n.d.). Retrieved from http://www.optomec.com/3dprinted-metals/lens-printers/low-cost-metal-3d-printer/

Lu, B., Ou, H., Shi, S. Q., Long, H., Chen, J. (2016). Titanium based cranial reconstruction using incremental sheet forming. International Journal of Material Forming, 9(3), 361-370.

Luo, Y., Yan, X., Qi, N., Wang, X., Wang, L. (2013). Study of double-side ultrasonic embossing for fabrication of microstructures on thermoplastic polymer substrates. PLOS ONE, 8(4). Retrieved from http://doi.org/10.1371/journal.pone.0061647

Mallik, M. K., Rao, C. S., Kesava Rao, V. V. S. (2014). Effect of heat treatment on hardness of Co-Cr-Mo alloy deposited with laser engineered net shaping. Procedia Engineering, 97, 1718-1723.

Mazzoli, A., Ferretti, C., Gigante, a, Salvolini, E., Mattioli-Belmonte, M. (2015). Selective laser sintering manufacturing of polycaprolactone bone scaffolds for applications in bone tissue engineering. Rapid Prototyping Journal, 21, 386-392.

Melchels, F. P. W., Feijen, J., Grijpma, D. W. (2010). A review on stereolithography and its applications in biomedical engineering. Biomaterials, 31(24), 6121-6130.

Moiduddin, K., Al-Ahmari, A., Kindi, M. Al, Nasr, E. S. A., Mohammad, A., Ramalingam, S. (2016). Customized porous implants by additive manufacturing for zygomatic reconstruction. Biocybernetics and Biomedical Engineering, 36(4), 719-730.

Murr, L. E. (2015). Metallurgy of additive manufacturing: Examples from electron beam melting. Additive Manufacturing, 5, 40-53.

Niu, F., Wu, D., Ma, G., Wang, J., Zhuang, J., \& Jin, Z. (2016). Rapid fabrication of eutectic ceramic structures by laser engineered net shaping. Procedia CIRP, 42(Isem Xviii), 91-95.

Pacurar, R., Pacurar, A. (2016). Applications of the Selective Laser Melting Technology in the Industrial and Medical Fields. In I. V Shishkovsky (Ed.), New Trends in 3D Printing. http://doi.org/10.5772/63038

Parthasarathy, J., Starly, B., Raman, S., Christensen, A. (2010). Mechanical evaluation of porous titanium (Ti6Al4V) structures with electron beam melting (EBM). Journal of the Mechanical Behavior of Biomedical Materials, 3(3), 249-259.

Paterson, A. M., Bibb, R., Campbell, R. I., \& Bingham, G. (2015). Comparing additive manufacturing technologies for customised wrist splints. Rapid Prototyping Journal, 21(3), 230-243.

Pattnaik, S., Karunakar, D. B., Jha, P. K. (2012). Developments in investment casting process - A review. Journal of Materials Processing Technology, 212(11), 2332-2348.

Polypropylene Suture. (n.d.).

Retrieved from http://www.unilene.com/Polypropilene-Sutures.html
Read, N., Wang, W., Essa, K., Attallah, M. M. (2015). Selective laser melting of AlSi10Mg alloy: Process optimisation and mechanical properties development. Materials and Design, 65, 417-424.

Salmi, M., Paloheimo, K. S., Tuomi, J., Wolff, J., Mäkitie, A. (2013). Accuracy of medical models made by additive manufacturing (rapid manufacturing). Journal of Cranio-Maxillofacial Surgery, 41(7), 603-609.

Singh, J., Singh, R., Singh, H. (2017). Dimensional accuracy and surface finish of biomedical implant fabricated as rapid investment casting for small to medium quantity production. Journal of Manufacturing Processes, 25 , 201-211.

Singh, R., Singh, S., Kapoor, P. (2014). Development of biomedical implant (hip joint) by combining fused deposition modelling and investment casting. Proceedings of the International Conference on Research and Innovations in Mechanical Engineering, 225-232.

Stansbury, J. W., Idacavage, M. J. (2016). 3D printing with polymers: Challenges among expanding options and opportunities. Dental Materials, 32(1), 54-64.

Stereolithography. Retrieved from https://www.stratasysdirect.com/solutions/stereolithography/

Suzuki, M., Ogawa, Y., Kawano, A., Hagiwara, A., Yamaguchi, H., Ono, H. (2004). Rapid prototyping of temporal bone for surgical training and medical education. Acta Oto-Laryngologica, 124(4), 400-402.

Tan, X., Kok, Y., Tan, Y. J., Descoins, M., Mangelinck, D., Tor, S. B., Leong, K. F., Chua, C. K. (2015). Graded microstructure and mechanical properties of additive manufactured Ti-6Al-4V via electron beam melting. Acta Materialia, 97, 1-16.

The Best SLA 3D Printers. Retrieved from https://all3dp.com/1/best-resin-dlpsla-3d-printer-kit-stereolithography/

Tiwari, S. K., Pande, S. (2014). Material properties and selection for selective laser sintering process. International Journal of Manufacturing Technology and Management, 27(4-5-6), 198-217.

Tumbleston, J. R., Shirvanyants, D., Ermoshkin, N., Janusziewicz, R., Johnson, A. R., Kelly, D., ... DeSimone, J. M. (2015). Continuous liquid interface production of 3D objects. Science, 347(6228), 1349-1352.

Ventola, C. L. (2014). Medical applications for 3D Printing: Current and projected uses. Pharmacy and Therapeutics, 39(10), 704-11.

Wall, D. L. (2012). Laser Micromachining. Medical Design Technology. Retrieved from https://resonetics.com/wpcontent/uploads/2016/04/MDT Resonetics.pdf

Wong, K. V., Hernandez, A. (2012). A review of additive manufacturing. ISRN Mechanical Engineering, 2012, 1-10.

Wurm, G., Tomancok, B., Holl, K., Trenkler, J. (2004). Prospective study on cranioplasty with individual carbon fiber reinforced polymere (CFRP) implants produced by means of stereolithography. Surgical Neurology, 62(6), 510-521.

Yadroitsev, I., Krakhmalev, P., Yadroitsava, I. (2014). Selective laser melting of Ti6Al4V alloy for biomedical applications: Temperature monitoring and microstructural evolution. Journal of Alloys and Compounds, 583(January), 404-409.

Yang, M., Zeng, Q., Vieira, M. P., Olsson, B. (2016). Three-Dimensional Printing in Dentistry: An Advanced Technology for Craniofacial Regeneration. In J. Wang \& Y. Lin (Eds.), Mesenchymal Stem Cells and Craniofacial Regeneration (pp. 33-59). Retrieved from https://books.google.com.my/books?hl=en\&lr=\&id=cM7nDQAAQBAJ\& $\mathrm{oi}=$ fnd\&pg $=$ PA33\&dq= continuous + liquid + interface + production $+($ clip $) \& o$ ts $=$ jsbN1mtYaZ\&sig=NywqVxlMifYyW4c_mtv8Gzt7iRI\&redir_esc $=y \# v$ $=$ onepage \&q=continuous liquid interface production (clip)\&f $=$ fals

Yap, Y. L., Tan, Y. S. E., Tan, H. K. J., Peh, Z. K., Low, X. Y., Yeong, W. Y., ... Laude, A. (2017). 3D printed bio-models for medical applications. Rapid Prototyping Journal, 23(2), 227-235.

Zhou, C., Ye, H., Zhang, F. (2015). A novel low-cost stereolithography process based on vector scanning and mask projection for high-accuracy, high-speed, high-throughput, and large-area fabrication. Journal of Computing and Information Science in Engineering, 15, 11003. 